\title{
A(S) DISCIPLINARIDADE(S) DA CIÊNCIA DA INFORMAÇÃO: APLICAÇÃO DAS LEIS DA DIALÉTICA MARXISTA NO CONTEXTO PLURI, INTER E TRANSDISCIPLINAR
}

\author{
THE DISCIPLINARITY(S) OF INFORMATION SCIENCE: APPLICATION \\ OF THE MARXIST DIALECTICS LAWS IN THE MULTI, INTER AND \\ TRANSDISCIPLINARY CONTEXT
}

Jonathas Luiz Carvalho Silva ${ }^{1}$

\begin{abstract}
Resumo: Discute sobre a construção disciplinar do conhecimento na Ciência da Informação a partir da aplicação das leis da dialética marxista. Apresenta como síntese problematizadora a seguinte pergunta: como é possível aplicar as leis/categorias da dialética marxista à Ciência da Informação? Tem como objetivo uma reflexão sobre a dialética marxista (materialista) e as formas de aplicação das leis da dialética à Ciência da Informação. A metodologia do presente estudo consiste de uma pesquisa de nível exploratório com delineamento bibliográfico. Concluímos que há possibilidades diversas de aplicação das leis da dialética marxista à Ciência da Informação, especialmente no que toca a lei da mudança qualitativa, a lei da ação recíproca e a lei da luta dos contrários. Porém, essas aplicações se estabelecem não como uma verdade, mas como pressupostos para compreender os significados do caráter disciplinar da Ciência da Informação no âmbito de suas transformações epistemológicas.
\end{abstract}

Palavras-chave: Ciência da Informação. Dialética - Leis - Categorias. Pluridisciplinaridade. Interdisciplinaridade. Transdisciplinaridade.

Abstract: Discusses the construction of disciplinary knowledge in Information Science from the application of the Marxist dialectic laws. Presents a synthesis problematizing the following question: how is it possible to apply the laws / categories of Marxist dialectics to Information Science? It aims to reflect on Marxist dialectics (materialistic) and forms of application of dialectics laws to Information Science. The methodology consists of an exploratory study with bibliographic design. Concludes that there are several possibilities for the application of the Marxist dialectic laws to Information Science, especially as regard to qualitative change law, reciprocal action law and struggle of opposite's law. However, these applications are established not as a fact, but as presuppositions for understanding the meanings of disciplinary information Science within its epistemological transformations.

Keywords: Social Network., Information Flows. Information Science.

\footnotetext{
${ }^{1}$ Professor do curso de Biblioteconomia da Universidade Federal do Ceará - Campus Cariri. Mestre em Ciência da Informação pela Universidade Federal da Paraíba (UFPB). E-mail: jonathascarvalhos@yahoo.com.br
}

Enviado em: 14/09/2012 - Aceito em: 03/03/2013.

\begin{tabular}{l|l|l|l|l|l|l|} 
(C) Rev. digit. bibliotecon. cienc. inf. & Campinas, SP & v.11 & n.2 & p.1-20 & maio/ago. 2013 & ISSN 1678-765X \\
\hline
\end{tabular}




\section{INTRODUÇÃO}

A Ciência da Informação vem se desenvolvendo rápida e amplamente como campo do conhecimento, mesmo sendo considerada uma ciência jovem. Esse desenvolvimento ocorre baseado em um constante processo de transformações, reflexões e contradições como é inerente a qualquer campo do conhecimento.

Um dos principais instrumentos para discussão sobre o desenvolvimento de um campo científico tem sido a sua configuração disciplinar. No caso da Ciência da Informação essa configuração disciplinar tem sido marcada como característica natural da área. As características disciplinares da Ciência da Informação vem sendo discutidas de forma acalorada como fenômeno de construção do conhecimento.

Conforme Lênine (1975, p. 123) o conhecimento pode ser definido como:

processo pelo qual o pensamento se aproxima infinita e eternamente do objeto. O reflexo da Natureza no pensamento humano deve ser compreendido não de maneira 'morta', não 'abstratamente', não sem movimento, não sem contradição, mas sim no processo eterno do movimento, do nascimento das contradições e sua resolução.

$\mathrm{O}$ conceito apresentado mostra o conhecimento enquanto elemento dialético de intensa movimentação e transformação. O conhecimento deve ser vivo e primar pelo desenvolvimento das contradições e de suas possíveis soluções, visando conotar mudanças de cunho qualitativo.

Assim, entendemos que a dialética, mais precisamente suas leis e categorias, podem contribuir para se pensar a construção disciplinar do conhecimento na Ciência da Informação e suas aplicações na perspectiva epistemológica da área.

$\mathrm{O}$ presente trabalho apresenta como síntese problematizadora a seguinte pergunta: como é possível aplicar as leis/categorias da dialética marxista à Ciência da Informação? Tem como objetivo uma reflexão sobre a dialética marxista (materialista) e as formas de aplicação das leis da dialética à Ciência da Informação.

\section{DAS CONCEPÇÕES DE LEIS E CATEGORIAS DIALÉTICAS: ALGUMAS CONSIDERAÇỖES PRELIMINARES}


As reflexões sobre o(s) conceito(s) de dialética possuem uma ampla trajetória no âmbito da História da Filosofia e das Ciências Humanas e Sociais com pressuposições e significações diversas.

Isso significa dizer que ao nos debruçarmos sobre a pergunta 'o que é dialética?' teremos uma multiplicidade de respostas contemplando questões temporais (a formação dos conceitos a partir das variações dos pensamentos na História da Filosofia) e temático-conceituais (estudiosos diversos que pensam a dialética no contexto das contradições, das transformações/movimentos, além das concepções da lógica e/ou da metafísica).

Gadotti (2006) destaca que alguns filósofos foram fundamentais para a elaboração do conceito de dialética, especialmente na China e na Grécia Antiga, tais como:

a) Tao Te Ching (primeiro pensador a incorporar o ideário de dialética no contexto da contradição); Zenão de Eléia (considera a dialética como filosofia da aparência);

b) Heráclito de Éfeso (a realidade é um constante devir, na qual prevalece a luta dos opostos); Parmênides de Eléia (o movimento era uma ilusão);

c) Parmênides (o movimento era uma ilusão e tudo era imutável);

d) Sócrates (o maior dialético da Grécia, pois utilizando a dúvida sistemática, procedendo por análises e sínteses, reconhecia que a verdade se estabelecia como um parto em que o mestre era apenas um provocador, enquanto o discípulo seria o verdadeiro criador);

e) Platão (a dialética seria um método de ascensão ao inteligível ou método de educação racional das ideias);

f) Aristóteles (a dialética era apenas auxiliar a Filosofia, pois não se configurava como um método para se chegar a verdade, mas como movimento que conduz o conhecimento à disputa, probabilidade ou opinião).

Assim, observamos que a dialética e suas bases originárias remontam a duas questões cruciais, sendo a primeira relativa a explicação do movimento e da transformação da realidade e a segunda os construtos norteados a partir das contradições (unidade dos opostos) que se constitui como um dos primados das leis dialéticas na contemporaneidade. 
É preciso ressaltar que na Idade Média e Moderna, a dialética foi subjugada como inútil ou desnecessária, já que no primeiro período, a Filosofia estava ligada aos processos teológicos e, no segundo período, a dialética se aproximava do pensamento aristotélico referente a uma lógica das aparências.

Conforme Lalande (1996) é a partir de Hegel que a dialética passa a ser retomada no âmbito das reflexões filosóficas como uma aplicação científica das leis inerentes a natureza e ao pensamento, assim como a síntese dos opostos em uma perspectiva eminentemente idealista.

Mas é a partir de Marx e Engels que a dialética restabelece seu status filosófico e científico (no movimento do materialismo dialético e materialismo histórico, respectivamente), de sorte que constitui novos fundamentos para construção do conhecimento a partir de uma crítica a dialética idealista (da consciência como dado primário) de Hegel.

Marx, ao contrário de Hegel, não considera que a consciência é um dado primeiro do movimento que leva compreensão da realidade, mas pondera sobre a primazia dos conteúdos materiais e históricos que manifestam formas infinitas da consciência. Logo, Marx rejeita a posição pensada à posição objetiva, pois para ele esta segunda transgressão só pode ser efetivada através da prática. (OLIVEIRA, 2004, p. 23).

Em outras palavras, Marx valoriza a dialética como método, construto de conhecimento e, especialmente, na relação entre o ser e o mundo que aproxima a teoria (conhecimento) da prática (ação), sendo que a construção de conhecimento deve ser composta a partir do real ou concreto (das configurações sociais, materiais e históricas), com vistas a transformação da realidade. ${ }^{2}$

Por isso, Marx (1983, p. 233-234) reitera uma percepção muito relevante para a discussão sobre a dialética em uma perspectiva materialista quando afirma que "Não

\footnotetext{
${ }^{2}$ No caso a transformação se evidencia na constante luta entre a burguesia e o proletariado no sistema capitalista. Esta luta reconhecidamente como 'luta dos contrários' demanda, na concepção dialética marxista, um processo de transformação que parte de um pressuposto concreto e real. Isso significa dizer que a dialética marxista se institui a partir dos movimentos de dominação e contradição constituídos por meio das forças produtivas (percepção concreta e real da realidade) quando o próprio Marx (1978, p. 16) afirma que "o homem torna-se cada vez mais pobre enquanto homem, precisa cada vez mais do dinheiro para apossar-se do seu inimigo, e o poder do seu dinheiro diminui em relação inversa à massa da produção."
} 
é a consciência dos homens que determina seu ser, mas, pelo contrário, o seu ser social que determina a sua consciência."

Vale destacar que é na configuração concreta e real que a dialética, enquanto método e fenômeno de construção do conhecimento se desenvolve a partir de um conjunto de leis e categorias. Essas leis foram desenvolvidas considerando os estudos de Hegel (dialética idealista), Marx/Engels (materialismo dialético e histórico) e os sucessores estudiosos do marxismo. Podemos definir 4 (quatro) leis da dialética marxista em oposição à metafísica, conforme nos revela Politzer (1970):

a) tudo se relaciona (lei da ação recíproca) - o método dialético designa que nenhum fenômeno da natureza pode ser compreendido, quando encarado isoladamente;

b) tudo se transforma (lei da transformação universal) - o movimento é uma qualidade inerente a realidade, ou seja, a dialética considera as transformações da realidade que se manifesta na natureza e na sociedade de forma inacabada. Esta lei está ligada a lei da negação da negação formulada por Engels (1976);

c) mudança qualitativa - revela a existência de uma relação entre as mudanças quantitativas e as mudanças qualitativas e que essa relação é uma lei universal da natureza e da sociedade;

d) luta dos contrários (contradição) - afirma que a contradição é interna, de sorte que revela a essência da transformação e também é inovadora, pois é tomada como uma luta entre o velho e o novo, entre o que morre e o que nasce e entre o que perece e o que se desenvolve. Leva em conta a unidade dos contrários, pois não há contradição, se não houver luta entre, pelo menos, duas forças que, embora se configurem como forças combatentes, são também forças inseparáveis.

É preciso observar que essas leis possuem uma diversidade de aplicações à sociedade, à natureza e a construção do conhecimento que envolve, neste estudo, a aplicação das leis da dialética a Ciência da informação e suas percepções disciplinares.

DA CONTRADIÇÃO E MOVIMENTO NA CONSTRUÇÃO DO CONHECIMENTO: AS LEIS DA DIALÉTICA MARXISTA APLICADAS AS PERCEPÇÕES DISCIPLINARES DA CIÊNCIA DA INFORMAÇÃO 
Consideramos que as leis da dialética supramencionadas no tópico anterior podem ser aplicadas à sociedade e ao conhecimento contemplando fundamentos históricos, materiais e naturais.

No presente trabalho, enfatizamos a aplicação das leis da dialética aos contextos disciplinares da Ciência da Informação podendo ser ratificada como dialética do conhecimento que segundo Mandel (1978, p.116) "é uma dialética sujeito-objeto, o resultado de uma interação constante entre os objetos a conhecer e a ação dos sujeitos que procuram conhecê-lo.”

\section{Aplicação da lei dialética da mudança qualitativa à Ciência da Informação: da pluridisciplinaridade à interdisciplinaridade}

A dialética em sua mudança da quantidade para qualidade requer um conjunto de expressões sociais e cognitivas que elucidem as propriedades, características, diferenças e semelhanças de uma determinada realidade/objeto/fenômeno. ${ }^{3}$

Todavia, essa segregação entre quantidade/qualidade não é tão exata ou precisa e muito menos simples de ser estabelecida, pois se a qualidade demanda as diferenças e semelhanças dos indícios da dialética significa dizer que quantidade e qualidade são muito mais indissociáveis do que opostos/excludentes.

Cheptulin (2004, p. 208), após uma discussão sobre a temática, além de seus determinantes e propriedades define "a qualidade como o conjunto das propriedades que indicam o que uma coisa dada representa, o que ela é, e a quantidade como o conjunto das propriedades que exprimem suas dimensões, sua grandeza." ${ }^{4}$ Assim, de forma recíproca, qualidade e quantidade contribuem para compreensão do que representa uma determinada coisa.

Diante dessa reflexão, como pensar a aplicação da lei dialética da mudança qualitativa no âmbito da disciplinaridade da Ciência da informação? Em primeira instância, pensamos que em uma dialética disciplinar da Ciência da informação, a

\footnotetext{
${ }^{3}$ Desse modo, é possível superar a ideia de que a qualidade é referente apenas aquilo que diferencia uma coisa das outras, mas também é inerente as condições de semelhança entre as outras coisas. (CHEPTULIN, 2004).

${ }^{4}$ Cheptulin (2004) mostra essa relação entre quantidade e qualidade quando exemplifica que cada ângulo é uma das propriedades de um triângulo, mas possui uma qualidade e quantidade rigorosamente definidas, sendo a qualidade o fato desse triângulo ser formado por círculos partindo de um mesmo ponto e que tenha outras propriedades, enquanto a quantidade é representada por sua grandeza concreta, sua dimensão, expressa em graus.
} 
quantidade poderia ser representada pela pluridisciplinaridade, enquanto a qualidade pela interdisciplinaridade da Ciência da Informação.

A pluridisciplinaridade pode ser entendida, conforme Dellatre (1973) como associação de disciplinas que concorrem para uma realização comum, mas sem que cada disciplina tenha que modificar sensivelmente a sua própria visão das coisas e os seus métodos próprios.

Já a interdisciplinaridade pode ser entendida aqui a partir de dois conceitos, sendo o primeiro de Piaget (1972) quando considera a interdisciplinaridade como intercâmbio mútuo e integração recíproca entre disciplinas variadas, visando um enriquecimento recíproco e o segundo de Palmade (1979) quando entende a interdisciplinaridade como uma integração interna e de concepção que rompe a estrutura de cada disciplina para construir novos axiomas com vistas a estabelecer uma visão unitária do saber.

Dessa maneira, a quantidade disciplinar da Ciência da Informação no desiderato da dialética imprime nas relações diversas que a Ciência da Informação pode constituir com outros campos do conhecimento e disciplinas sem que ocorram interferências diretas (unilaterais ou mútuas) entre essas áreas. Por exemplo, a quantidade da dialética da Ciência da Informação ocorre em um contexto pluridisciplinar no que toca a relação com várias disciplinas/campos do conhecimento referentes às Ciências Humanas/Sociais, Exatas, Tecnológicas, Agrárias, Saúde, entre outras e a representação de conteúdos em comum entre a Ciência da Informação e essas disciplinas/campos do conhecimento.

Já a qualidade disciplinar da Ciência da Informação como fundamento dialético, ocorre quando há um fechamento mais efetivo das relações disciplinares entre a Ciência da Informação e outras disciplinas/campos do conhecimento havendo uma interferência recíproca.

Por exemplo, entre a Ciência da Informação e a Linguística devemos ponderar como processo de uma mudança dialética qualitativa a natureza entre informação e linguagem, além da Pragmática que envolve a análise do discurso que pode ser agregada no processo de análise documentária, representação e recuperação da informação constituindo uma propriedade qualitativa de semelhança e de interferência recíproca entre estes campos do conhecimento. Como afirma Baranow (1983) os 
enfoques pragmáticos permitem novas soluções para problemas de ambigüidade semântica e sintática, que são de importância crucial na recuperação da informação.

E como se dá essa mudança dialético-disciplinar da quantidade (pluridisciplinaridade) para a qualidade (interdisciplinaridade) na Ciência da Informação?

É preciso observar o processo da dialética do conhecimento a partir da relação entre sujeito-objeto, suas possibilidades de interpretação da realidade, suas contradições e movimentos na construção do conhecimento, bem como as condições particulares, institucionais e de construção do conhecimento da pesquisa/pesquisador, curso/programa em Ciência da Informação. Consideramos preliminarmente que a dialética é fundamentada a partir de uma mudança qualitativa. Como afirma Luckács (1970, p. 260) a dialética se constitui no âmbito da "formação ininterrupta da novidade qualitativa."

A priori, as condições para uma dialética quantitativa é determinante quando da inserção (não necessariamente recíproca) de muitos conteúdos (atividades de pesquisa, artigos, projetos e outros textos acadêmico-científicos) envolvendo a Ciência da Informação e outros campos do conhecimento.

A partir desse determinante quantitativo, é possível observar uma perspectiva de mudança qualitativa no âmbito de uma relação social e institucional mais concreta entre a Ciência da informação e o(s) campo(s) do conhecimento desejáveis para constituir uma ação recíproca e integração interna.

Logo, é possível perceber que essa mudança dialética qualitativa da pluridisciplinaridade para a interdisciplinaridade na Ciência da Informação com outros campos do conhecimento é imanente aos contextos locais e particulares do pesquisador/pesquisa e curso/programa.

Contudo, essa dialética da mudança qualitativa só pode ocorrer a partir de uma negação de que a Ciência da Informação não é interdisciplinar com qualquer campo do conhecimento e em qualquer contexto, pois essa interdisciplinaridade só é possível através de ações recíprocas que contribuem para um desenvolvimento coletivo de conhecimento. 
A negação de uma interdisciplinaridade aleatória ou natural da Ciência da Informação está sensivelmente debruçada em uma justaposição sumária da construção pluridisciplinar do conhecimento (procedimento sumário da dialética quantitativa).

Outrossim, essa negação pode ser constatada na percepção de Bicalho e Oliveira (2011) quando afirmam que a interdisciplinaridade tem sido lugar comum quando associado à Ciência da Informação, mas, na sua literatura, não está devidamente colocado o seu significado enquanto característica marcante e identitária e também em Pinheiro (1999, p.175-176) quando destaca que "[...] a Ciência da Informação incorpora muito mais contribuições de outras áreas, do que transfere para essas um corpo de conhecimentos gerados dentro de si mesma."

Assim, a mudança dialética da qualidade na Ciência da Informação reside na construção crítica de que a pluridisciplinaridade é um fundamento primário quantitativo e que a interdisciplinaridade se constitui na negação da pluridisciplinaridade quantitativa para ser constituída e passível de efetividade ${ }^{5}$, enquanto aspecto dialético do conhecimento.

Por exemplo, em um Programa de Pós-Graduação em Ciência da Informação que contemple como base as linhas de gestão e tecnologia é provável uma mudança dialética da quantidade para a qualidade quando a quantidade determina as diversas relações possíveis da Ciência da Informação com os campos do conhecimento (pluridisciplinaridade) e suas representações conteudísticas dos artigos e projetos desenvolvidos no Programa (seja relativo à Ciência da Informação ou a outros campos do conhecimento sem uma interferência direta entre esses campos) e a qualidade representa o afunilamento dessas concepções pluridisciplinares quando há um contato concreto/direto entre a Ciência da informação e outros campos do conhecimento relativos as linhas de gestão e tecnologias, como a Administração e a Ciência da Computação, respectivamente, constituindo uma interferência direta entre esses campos do conhecimento. Essa aproximação interdisciplinar estabelece não somente as diferenças, mas também as semelhanças e peculiaridades que são marcas das propriedades da lei dialética da mudança qualitativa. (CHEPTULIN, 2004).

\footnotetext{
${ }^{5}$ A efetividade interdisciplinar é entendida aqui no argumento de Oliveira (2004, p. 68) quando elucida que "a efetividade é o fenômeno enquanto fenômeno da essência, a unidade posta da essência e do fenômeno." Logo, a interdisciplinaridade da Ciência da informação está situada na essência de suas ações recíprocas com outros campos do conhecimento.
} 


\section{Aplicação da lei dialética da ação recíproca à Ciência da Informação: a formação do materialismo interdisciplinar do conhecimento}

A dialética, enquanto método e concepção lógica do conhecimento possui fundamentos efetivos no que tange ao movimento, relação entre os fenômenos, transformação da realidade, contradição/antinomia, afirmação/negação/negação / negação da negação. (FAUSTO, 1987).

A lei da ação recíproca invoca os fundamentos categoriais dialéticos da transformação ontológica no que toca ao relacionamento das coisas, além dos movimentos e negações causados por essas relações. Segundo Engels (1877, p. 392) "a dialética considera as coisas e os conceitos no seu encadeamento; suas relações mútuas, sua ação recíproca e as decorrentes modificações mútuas, seu nascimento, seu desenvolvimento, sua decadência."

Consideramos que a ação recíproca, como fenômeno dialético, possui um significado que se aproxima da percepção conceitual de interdisciplinaridade. Politzer (1970) afirma que essa lei tem grande importância prática, pois quando se analisa separadamente um fragmento da realidade, deslocado de seu contexto político, há um abandono da dialética porque, esta, ensina que tudo se relaciona.

Da mesma forma, consideramos que se não há um pensamento, um discurso e uma ação recíproca, a aplicação da interdisciplinaridade é abandonada. O comentário de Fazenda (1994, p.28-29) identifica uma estreita relação conceitual e aplicativa entre a lei dialética da ação recíproca e a interdisciplinaridade:

\footnotetext{
Interdisciplinaridade não é categoria de conhecimento, mas de ação; a interdisciplinaridade nos conduz a um exercício de conhecimento: o perguntar e o duvidar; interdisciplinaridade é a arte do tecido que nunca deixa ocorrer o divórcio entre seus elementos, entretanto, de um tecido bem trançado e flexível. A interdisciplinaridade se desenvolve a partir do desenvolvimento das próprias disciplinas.
}

A interdisciplinaridade tem como finalidade superar a fragmentação e o caráter de especialização do conhecimento, causados por uma epistemologia de tendência positivista em cujas raízes estão o empirismo, o naturalismo e o 
mecanicismo científico do início da modernidade. A interdisciplinaridade deve ser vista não somente como fenômeno epistemológico e pedagógico, mas também político e cultural, haja vista que está relacionada aos diversos contextos da humanidade. (GADOTTI, 1999).

Para tanto, compreendemos que a interdisciplinaridade só pode ser concebida como instrumento de ação recíproca. Essa ação recíproca é constituinte de um processo dialético marxista que vai da prática a concepção teórica de construção do conhecimento.

Por isso, é preciso atentar para o fato de que a interdisciplinaridade na Ciência da Informação não pode ser simplesmente considerada como fenômeno natural ou conformista, mas sim como fenômeno a ser constituído e conquistado da prática à concepção teórica de forma coletiva, integrada e autônoma.

Isso significa dizer que a interdisciplinaridade é fruto das configurações sociais que vai firmando a consciência coletiva e constituindo um novo corpus aplicativo e epistemológico para a Ciência da Informação por meio de um reconhecimento mútuo e relegando a um plano inferior a concepção natural, positivista e/ou metafísica de que a Ciência da Informação possui natureza interdisciplinar.

Em outras palavras, a interdisciplinaridade na Ciência da Informação é categoria de ação (recíproca, de integração e interação) que nos conduz a construção do conhecimento ou a formação de uma nova consciência confirmando o ideário marxiano de que o ser social engendra a consciência. (MARX, 1983).

É possível perceber no cotidiano social e epistemológico da Ciência da Informação a formação heurística de um pensamento positivista da interdisciplinaridade como elemento arbitrariamente imposto, sem considerar essa interdisciplinaridade como fundamento dialético de ação recíproca que se institui como afirmação do pensamento lógico do conhecimento na Ciência da Informação.

Todavia, é preciso superar esta percepção negando-a como subsídio viável para o amadurecimento social e epistemológico da Ciência da Informação. A dialética interdisciplinar do conhecimento na Ciência da Informação deve ser respaldada na conquista prática através da formação relacional cotidiana com outros campos do 
conhecimento, visando a sua constatação de elemento de ação e não simplesmente de um conhecimento discursivo.

Essa relação recíproca e direto-concreta com outros campos do conhecimento, buscando uma contribuição mútua entre as áreas é que poderá promover à Ciência da Informação um status real de interdisciplinar reconhecendo na mutualidade ontológica e de adequação recíproca a formação de um corpus epistemológico dinâmico e conquistado da prática à teoria e não apenas no discurso interno da área.

Para detalhar de forma mais efetiva esse desiderato dialético-interdisciplinar da Ciência da Informação como instrumento de ação recíproca nos remete a baila a reflexão sobre a dialética.

\section{Aplicação da lei dialética da luta dos contrários à Ciência da Informação: a tríade afirmação pluridisciplinar/negação interdisciplinar/negação da negação transdisciplinar}

A luta dos contrários é constantemente discutida no âmbito das teorias marxianas e marxistas. A contradição é o motor da luta dos contrários que se configura no eterno devir social e cognitivo e que se institui na formulação da diferença (constituem a forma geral do ser a partir da qual as contradições são desenvolvidas) e da identidade (a interpenetração dos contrários um no outro).

Isso significa dizer que a luta dos contrários não se resume apenas ao que é diferente ou contraditório, mas também a uma unidade dos contrários (passagem dos contrários um no outro) que se assume como fundamento de sustentação da dialética. Não é a toa que Lênine (1989, p.107) afirma ser a dialética uma teoria que "mostra como os contrários podem ser e são habitualmente (e tornam-se) idênticos ao converterem-se um no outro - - por que razão o entendimento humano não deve tomar esses contrários por mortos, petrificados, mas sim por vivos, condicionados, móveis, convertendo-se um no outro."

Observamos que nesse conceito, os processos conteudísticos da dialética são revelados considerando as perspectivas da contradição enquanto fenômeno da dinamicidade lógica e ontológica do caráter prático e teórico do conhecimento. É possível dizer ainda que nessa concepção dialética a luta dos contrários amadurecem não apenas pela sua perspectiva de contradição (oposição), mas especialmente pelas suas (in)tensas interpenetrações que torna os contrários idênticos. 
Essa passagem constante na luta dos contrários (conotação de identidade no sentido de coincidência da natureza) é que permite pensar a realidade dos fenômenos como viva, transformadora e atribuir procedimentos de diferença (que levam a efetivação das contradições) constituindo a unidade dos contrários. A unidade dos contrários é definida por Cheptulin (2004, p.287) como "seu estabelecimento recíproco, isto é, os aspectos ou tendências contrários não podem existir uns sem os outros."

E qual a relação dessa luta dos contrários e unidade dos contrários com uma dialética disciplinar na Ciência da Informação? Em primeira instância, essa relação reside na tríade disciplinar da pluridisciplinaridade, interdisciplinaridade, transdisciplinaridade. A pluridisciplinaridade é reconhecida como momento de afirmação na Ciência da Informação e alegações sociais para construção do conhecimento. A interdisciplinaridade é reconhecida como momento de negação na Ciência da informação, de modo que se manifesta como elemento contrário a pluridisciplinaridade.

Dessa maneira, a eterna luta dos contrários na Ciência da Informação ocorre entre a pluridisciplinaridade (afirmação) e a interdiscipinaridade (negação). Essa luta de contrários permite pensar as contradições epistemológicas da Ciência da Informação que se circunscreve em seu âmbito de atuação acadêmica, científica, social e profissional.

Essa luta dos contrários ocorre quando a afirmação dialética pluridisciplinar reconhece a Ciência da Informação relacionada a uma multiplicidade de campos/disciplinas sem ligações ou interferências diretas. A negação dialética interdisciplinar ocorre quando rejeita essa ligação aleatória, sem perspectivas mais sólidas e de interferências diretas considerando que uma relação interdisciplinar exige reciprocidade.

Contudo, essa negação dialética interdisciplinar na Ciência da Informação não tem como objetivo simplesmente destruir ou menosprezar a afirmação dialética pluridisciplinar. A negação dialética, sendo uma consequiência da evolução e da resolução das contradições próprias a formação material negada, não é uma simples destruição de um determinismo qualitativo, mas representa uma negação no curso da qual tudo o que havia de positivo no estado negado (em nosso caso a 
pluridisciplinaridade) está retido para um estado qualitativo novo (em nosso caso a transdisciplinaridade). (CHEPTULIN, 2004).

Essa mudança qualitativa entre a afirmação dialética pluridisciplinar e a negação dialética interdisciplinar se configura na passagem de uma luta dos contrários para uma unidade dos contrários quando há uma transformação recíproca entre pluridisciplinaridade e interdisciplinaridade reconhecendo seus potenciais de transformação para uma nova qualidade.

O nome dessa nova qualidade é a transdisciplinaridade que se estabelece como terceiro fenômeno intitulado negação da negação (novo estado) dos dois primeiros fenômenos (em eterna luta dos contrários). Pombo (1994, p. 13) permite pensar na passagem para o novo estado qualitativo da transdisciplinaridade quando a conceitua como:

[...] unificação de duas ou mais disciplinas tendo por base a explicitação dos seus fundamentos comuns, a construção de uma linguagem comum, a identificação de estruturas e mecanismos comuns de compreensão do real, a formulação de uma visão unitária e sistemática de um setor mais ou menos alargado do saber.

Percebemos que ocorre na transdisciplinaridade a consolidação da unidade dos contrários em face da unificação de duas ou mais disciplinas com fundamentos e linguagens em comum.

No que toca a Ciência da Informação é possível atentar que em termos de uma afirmação pluridisciplinar pode estar ligada a qualquer campo do conhecimento por meio de relações indiretas, como a leitura de textos de outras áreas do conhecimento e o uso dos textos de outras áreas para construção dos conteúdos de pesquisa em Ciência da Informação. Essa ligação pode ocorrer com diversas áreas do conhecimento de forma mais expressiva no âmbito da pesquisa, como as Ciências da Saúde, Ciências Exatas, Tecnologias (Computação, Engenharia de Produção, etc.), entre outras.

Já a negação dialética interdisciplinar demanda uma ação recíproca mais efetiva, tanto no âmbito dos conteúdos de pesquisa, quanto de ensino e das práticas cotidianas, como, por exemplo, entre a Ciência da Informação e a: Psicologia (Estudo de usuários (comportamento do usuário, necessidades e usos da informação); 
Linguística (análise documentária; representação e recuperação da informação); Ciência da Computação (Representação da informação; Sistemas de recuperação da informação; Inteligência Artificial e Tecnologias da informação e comunicação); Comunicação (Tecnologias da informação e comunicação e Comunicação da informação científica e tecnológica); Filosofia (Filosofia da informação, epistemologia e representação da informação; Sociologia (fundamentos sociais, a sociedade da informação, sociologia da ciência, sociologia do conhecimento, Comunicação da informação científica e tecnológica e Estudos métricos da informação); História (estudos sobre arquivo, museu e preservação da memória); Administração (Gestão da Informação; Gestão do Conhecimento; Inteligência Competitiva; Planejamento e administração de unidades de informação; Tecnologias de Informação e Comunicação e Economia da informação); Economia (Gestão da Informação; Gestão do Conhecimento; Inteligência Competitiva; Economia da informação e Avaliação de custo/benefício); Ciências da Saúde (estudos sobre metrias de informação (bibliometria, cienciometria, informetria e webometria) aplicados a produção na área da Saúde; competência em informação na área de Saúde; políticas de informação científica e tecnológica no âmbito da Saúde). (PINHEIRO, 2006; MIKHAILOV, CHERNYI E GILYAREVSKYI 1969; SARACEVIC 1992).

É possível perceber que algumas disciplinas podem estabelecer relações pluri e interdisciplinares com a Ciência da Informação a depender dos seus estados de mudança quantitativa/qualitativa, assim como das condições gerais e particulares que norteiam cada continente, país, região, estado e município. O fato é que em uma relação pluridisciplinar com a Ciência da Informação as ligações são mais indiretas e/ou unilaterais, enquanto na relação interdisciplinar há o primado da reciprocidade.

Com efeito, para uma consolidação dialético-transdisciplinar da Ciência da Informação entendemos que se efetiva com a Biblioteconomia, de sorte que ambas possuem a construção de pressupostos teóricos, epistemológicos, históricos e materiais em comum que se estabelecem em um constante processo de movimento e contradição. Esse movimento dialético-transdisciplinar pode ser constatado nas condições de ensino, pesquisa, extensão das universidades e nas práticas profissionais de bibliotecários, além dos aparatos institucionais (vinculações departamentais). 
Essa percepção dialético-transdisciplinar entre Ciência da Informação e Biblioteconomia pode ser explicitada como a efetividade da unidade dos contrários (uma fusão unificadora) por meio de Pombo (2003, p. 3) que afirma:

\footnotetext{
"quanto à transdisciplinaridade, ela remeteria para qualquer coisa da ordem da fusão unificadora, solução final que, conforme as circunstâncias concretas e o campo específico de aplicação.”
}

Vale ressaltar que essa configuração dialético-transdisciplinar pode ser percebida de forma menos intensa entre a Ciência da Informação e a Arquivologia/Museologia, de modo que há muitas polêmicas político-institucionais e acadêmico-científicas que tornam essa dialética disciplinar, uma lógica do provável como designado por Aristóteles (ABBAGNANO, 2003) ou uma eterna luta dos contrários que fundamenta a dialética do conhecimento e que se desenvolve a partir de diversas heurísticas afirmativas/negativas, gerais/particulares, singulares/plurais, conscientes/inconscientes, diretas/indiretas e individuais/coletivas.

Vale ressaltar que essa dialética como instrumento de uma lógica do provável concebida por Aristóteles também pode ocorrer na relação entre a Ciência da Informação e outros campos do conhecimento, assim como ser estendida as outras leis da dialética, pois a construção de uma dialética disciplinar não é discursiva, mas depende de ações inerentes aos contextos acadêmicos, científicos e institucionais, como a relação entre Programas de Pós-Graduação, entre pesquisadores, etc.

\section{CONSIDERAÇÕES FINAIS}

A Ciência da Informação se constitui como campo do conhecimento em constante processo de transformação histórica, material, teórica, epistemológica e prática. Vale ressaltar que essas transformações são repletas de contradições (afirmações/negações) que podem ser elucidadas por meio de uma construção dialética e de princípios, leis e categorias dessa dialética do conhecimento que se configuram na relação entre a Ciência da Informação (pesquisa, ensino, eventos, periódicos) e os seus componentes humanos (pesquisadores), materiais/institucionais (programas de pós-graduações, departamentos, associações, entre outros). 
Observamos que um dos grandes trunfos para se pensar a dialética do conhecimento na Ciência da Informação está em sua concepção disciplinar amparada pelo contexto triádico da pluridisciplinaridade, interdisciplinaridade e transdisciplinaridade e que essa construção disciplinar do conhecimento pode ser compreendida no âmbito de aplicação das leis/categorias da dialética marxista.

Assim, percebemos que a pluridisciplinaridade e a interdisciplinaridade estão inseridas em um intenso espectro dialético do conhecimento da Ciência da Informação no que tange a aplicação da lei da mudança qualitativa em que a pluridisciplinaridade se estabelece como aparato dialético quantitativo e a interdisciplinaridade como aparato dialético qualitativo.

Verificamos também a aplicação da lei dialética da ação recíproca no que toca a interdisciplinaridade da Ciência da Informação se constituindo como núcleo materializante de sua configuração epistemológica de pesquisa, ensino e ação institucional com outras áreas do conhecimento.

Entendemos que o ápice da dialética do conhecimento da Ciência da Informação pode ser concebido em uma (in)tensa luta dos contrário na Ciência da Informação entre pluridisciplinaridade que se caracteriza como uma afirmação, a interdisciplinaridade que se identifica como negação. A eterna luta desses contrários não deve ser vista apenas como uma oposição, mas também como um processo de diferenciação e semelhança ocorrendo uma interpenetração desses dois elementos e criando um terceiro estágio qualitativo (nova mudança da qualidade dialéticodisciplinar). Essa mudança qualitativa pode ser constituída como a postulação transdisciplinar da Ciência da Informação.

É possível constatar que a pluridisciplinaridade da Ciência da Informação enquanto afirmação pode ocorrer em diversos contextos particulares e gerais. Já a interdisciplinaridade se dá em um contexto mais específico com outros campos do conhecimento constituindo um movimento dinâmico de ação recíproca em que tanto a Ciência da Informação deve contribuir para uma determinada área do conhecimento como essa área deve contribuir para o desenvolvimento teórico-epistemológico e prático da Ciência da Informação. Essa percepção dialético-interdisciplinar pode ocorrer entre a Ciência da informação e Psicologia; Linguística; Ciência da 
Computação; Comunicação; Filosofia; Sociologia; História; Administração;

Economia; Ciências da Saúde.

A transdisciplinaridade ocorre em um momento muito particular da Ciência da Informação com a Biblioteconomia, pois o seu caráter de unidade dos contrários, seja no ensino, pesquisa, nas questões institucionais e das práticas do cotidiano é resultante de um amplo processo de luta e movimentação disciplinar.

Finalmente, acreditamos que a dialética disciplinar do conhecimento na Ciência da Informação apresentada no presente trabalho não busca estabelecer uma verdade, mas conceber elementos para a discussão sobre o que pode ser (ou vir a ser) a disciplinaridade na Ciência da Informação, atentando que a dialética enquanto construto do conhecimento e método pode contribuir, sobretudo a partir de suas leis/categorias, para aguçar e amadurecer as percepções disciplinares da Ciência da informação em suas diversas nuances. 


\section{REFERÊNCIAS}

ABBAGNANO, N. Dicionário de Filosofia. 4 ed. São Paulo: Martins Fontes, 2003.

BARANOW, U. G. Perspectivas na contribuição da lingüística e de áreas afins a ciência da informação. Ciência da Informação, Brasília, v. 12, n. 1, p. 23-35, 1983.

BICALHO, L.; OLIVEIRA, M. A teoria e a prática da interdisciplinaridade em Ciência da Informação. Perspectivas em Ciência da Informação, v.16, n.13 p.47-74, jul./set. 2011.

CHEPTULIN, A. A dialética materialista: categorias e leis da dialética. São Paulo: Editora Alfa-Omega, 2004.

DELATTRE, P. Recherches Interdisciplinaires. Objectifs et Difficultés. In: GUIMARÃES, H. M. et al (Orgs.), Antologia II. Lisboa: Projecto Mathesis, Departamento de Educação da Faculdade de Ciências de Lisboa, 1973. p.183-212.

ENGELS, F. Anti-Dühring.1877. Disponível em: <http://www.marxists.org/portugues/marx/1877/antiduhring/index.htm>. Acesso em: 12 set. 2012.

ENGELS, F. Dialética da natureza. Rio de Janeiro: Paz e Terra, 1976.

FAUSTO, R. Marx: Lógica e Política. São Paulo: Brasiliense, 1987.

FAZENDA, I. C. A. Interdisciplinaridade: história, teoria e pesquisa. Campinas: Papirus, 1994.

GADOTTI, M. Concepção dialética da educação. 15. ed. São Paulo: Cortez, 2006.

GADOTTI, M. Interdisciplinaridade: atitude e método. 1999. São Paulo: Instituto Paulo Freire. Disponível em:

<http://siteantigo.paulofreire.org/pub/Institu/SubInstitucional1203023491It003Ps002/Interdis ci_Atitude_Metodo_1999.pdf>. Acesso em: 04 nov. 2011.

MARX, K. Contribuição à crítica da economia política. São Paulo: Martins Fontes, 1983.

MARX, K. Manuscritos econômicos e filosóficos. Tradução de José Carlos Bruni. São Paulo: Abril Cultural, 1978.

LALANDE, A. Vocabulário técnico e crítico da filosofia. São Paulo: Martins Fontes, 1996.

LÊNINE, V. I. Conspecto do livro de Hegel "Ciência da Lógica" (1914). In: Obras escolhidas de Lénine em seis tomos. Moscou: Progresso; Lisboa: Avante. 1989. Vol.6.

LÊNINE, V. I. Os cadernos sobre a dialética de Hegel. Lisboa: Editorial Minerva, 1975.

LUKACS, G. Geschichte und Klassenbewusstsein. Neuwied \& Berlim: Luchterhand, 1970.

MANDEL, Ernest. Introdução ao marxismo. Porto Alegre: Movimento, 1978. 
MIKHAILOV, A. I.; CHERNYI, A. I.; GILYAREVSKYI, R.S. Informatics: its scope and methods. In: MILHAILOV, A. On theoretical problems of informatics. Moscou: FID /

Comitê de Estudo sobre Pesquisa de Base teórica da informação, p.7-24, 1969. (FID 435).

OLIVEIRA, M. A. Dialética hoje: lógica, metafísica e historicidade. São

Paulo: Loyola, 2004.

PALMADE, G. Interdisciplinaridade e Ideologias. Madrid: Narcea, 1979.

PIAGET, J. Méthodologie des Relations Interdisciplinaires. Archives de Philosophie, 34, 539-549, 1972.

PINHEIRO, L. V. R. Campo interdisciplinar da Ciência da Informação: fronteiras remotas e recentes. In: Ciência da Informação, Ciências Sociais e

interdisciplinaridade. Brasília: IBICT/DEP/DDI, 1999. p.155-178.

PINHEIRO, L. V. R. Ciência da Informação: desdobramentos disciplinares, interdisciplinaridade e transdisciplinaridade, 2006. Disponível em:

<http://www.uff.br/ppgci/editais/lenavanialeituras.pdf>. Acesso em: 21 jan. 2011.

POLITZER, G. et al. Princípios fundamentais da filosofia. São Paulo: Hemus, 1970.

POMBO, O. Epistemologia da Interdisciplinaridade. Cátedra Humanismo Latino, 2003.

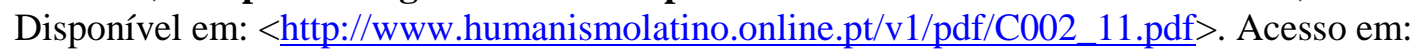
09 nov. 2011.

POMBO, O. Interdisciplinaridade: conceito, problema e perspectiva. In: POMBO, O. A interdisciplinaridade: reflexão e experiência. 2 ed. Lisboa: Universidade de Lisboa, 1994. Disponível em: <http://www.educ.fc.ul.pt/docentes/opombo/mathesis/interdisciplinaridade. pdf $>$. Acesso em: 18 out. 2011.

SARACEVIC, T. Information Science: origin, evolution and relations. In:

VAKKARI, P.; CRONIN, B. (Eds.). Conceptions of Library and Information Science: historical, empirical and theoretical perspectives. In: CONFERENCE FOR THE CELEBRATION OF 20TH ANNIVERSARY OF THE DEPARTMENT OF INFORMATION STUDIES, 1991, University of Tampere, Finland. Proceedings... Los Angeles: Taylor Graham, 1992. p. 5-27.

\section{Como citar este artigo:}

CARVALHO SILVA, Jonathas Luiz. A(s) disciplinaridade(s) da Ciência da Informação: aplicação das leis da dialética marxista no contexto pluri, inter e transdisciplinar. Rev. digit. bibliotecon. cienc. inf., Campinas, SP, v. 11, n. 2, p.1-20, maio/ago. 2013. ISSN 1678-765X. Disponível em: <http://www.sbu.unicamp.br/seer/ojs/index.php/rbci> 